\title{
Aortopulmonary fenestration and aortic atresia Report of an infant with ventricular septal defect,
persistent ductus arteriosus, and interrupted aortic arch
}

\author{
G. C. Rosenquist, ${ }^{2}$ J. F. N. Taylor, and J. Stark \\ From the Thoracic Unit, The Hospital for Sick Children, London
}

$A$ case report is presented of an infant with aortopulmonary fenestration, aortic atresia, interrupted aortic arch, persistent ductus arteriosus, and ventricular septal defect. Because of the aortic atresia, blood flow across the fenestration was the reverse of that usually seen in aortopulmonary defects.

Most reported cases of aortopulmonary fenestration are discrete openings between the main pulmonary artery and the aorta, distal to the outflow valves, and thus are amenable to surgical correction using cardiopulmonary bypass (Bosher and McCue, 1962; Deverall et al., 1969; Gross, I952; Gasul, Fell, and Casas, 195I ; Hurwitz, Ruttenberg, and Fonkalsrud, 1967; Kalter et al., 1970; Meisner et al., 1968; Morrow, Greenfield, and Braunwald, 1962; Neufeld et al., 1962; Putnam and Gross, 1966; Reis et al., 1965; Stanley et al., 1969; Wright, Freeman, and Johnston, 1968). Some cases are more difficult to correct because the fenestration is so large that there is either no truncal septum separating the aorta from the main pulmonary artery with only a very small cuff or rim above the separate valves, or an aortopulmonary fenestration that perches above both valves with no rim of tissue above the valves (Dadds and Hoyle, 1949; Sprengel and Brown, I954). Such cases have sometimes been classified as truncus arteriosus because one great vessel leads to pulmonary, systemic, and coronary circulations (Van Praagh and Van Praagh, 1965).

The present case report concerns an infant with aortopulmonary fenestration, aortic atresia, interrupted aortic arch, persistent ductus arteriosus, and ventricular septal defect. Because of the aortic atresia, blood flow across the fenestration was the reverse of that usually seen in aortopulmonary defects.

${ }^{1}$ Supported by grants from the National Institutes of Health (G.C.R.) and by the British Heart Foundation (J.F.N.T. and J.S.)

${ }^{2}$ Present address: CMSC 6-122 Johns Hopkins Hospital, Baltimore, Maryland 21205, U.S.A.

\section{Case report}

This 3-week-old boy was born normally at full term weighing $3.05 \mathrm{~kg}$. At 2 weeks of age he was in congestive heart failure. A loud systolic murmur was heard over the praecordium; and the second sound was single. The pulse in the right arm was more forceful than the left. The femoral pulses were weak. A chest $x$-ray showed a large heart with increased pulmonary vascularity. The electrocardiogram indicated an excess of left ventricular activity for the infant's age. Treatment with digoxin and diuretics (chlorothiazide) together with sedation failed to improve the cardiac failure. Cardiac catheterization and angiography at 20 days of age showed a ventricular septal defect and interruption of the aortic arch. The femoral artery pressure $(54 / 40 \mathrm{mmHg}$ ) was about half the pulmonary artery pressure $(100 / 50 \mathrm{mmHg})$, and femoral artery oxygen saturation was $81 \%$. On the day after the investigation, at 3 weeks of age, he died suddenly.

At necropsy the venae cavae entered the right atrium normally. The foramen ovale was patent. The tricuspid valve was normal, and measured $10 \mathrm{~mm}$ in diameter. The right ventricle was dilated and hypertrophied. The pulmonary valve was bicuspid and enlarged $(8 \mathrm{~mm}$ in diameter, Fig. IA). The ventricular septal defect was $6 \mathrm{~mm}$ in diameter. Its superior margin was fibrous tissue that separated the pulmonary annulus from the atretic left ventricular outflow tract. The septal band formed the anterior margin of the defect; the inferior and posterior margins were formed by the parietal band of the crista supraventricularis (Fig. IA). The intact membranous ventricular septum (pars membranacea) was normally situated under the parietal band. The main, right, and left pulmonary arteries were dilated. A partially constricted persistent ductus arteriosus $(2.5 \mathrm{~mm}$ in diameter, Fig. IA) gave access to the left subclavian artery and descending aorta $(4.5 \mathrm{~mm}$ in diameter). The oval communication between the main pulmonary artery 
and the ascending aorta measured $4 \times 6 \mathrm{~mm}$. A 2-mm cuff or rim of tissue separated the origins of the great vessels and formed the proximal margin of the fenestration (Fig. IA). The atretic aortic valve was located adjacent to the left ventricular outflow tract (Fig. IB). The coronary arteries arose from the hypoplastic aortic sinuses (Fig. IB). The aorta was $4 \mathrm{~mm}$ in diameter and

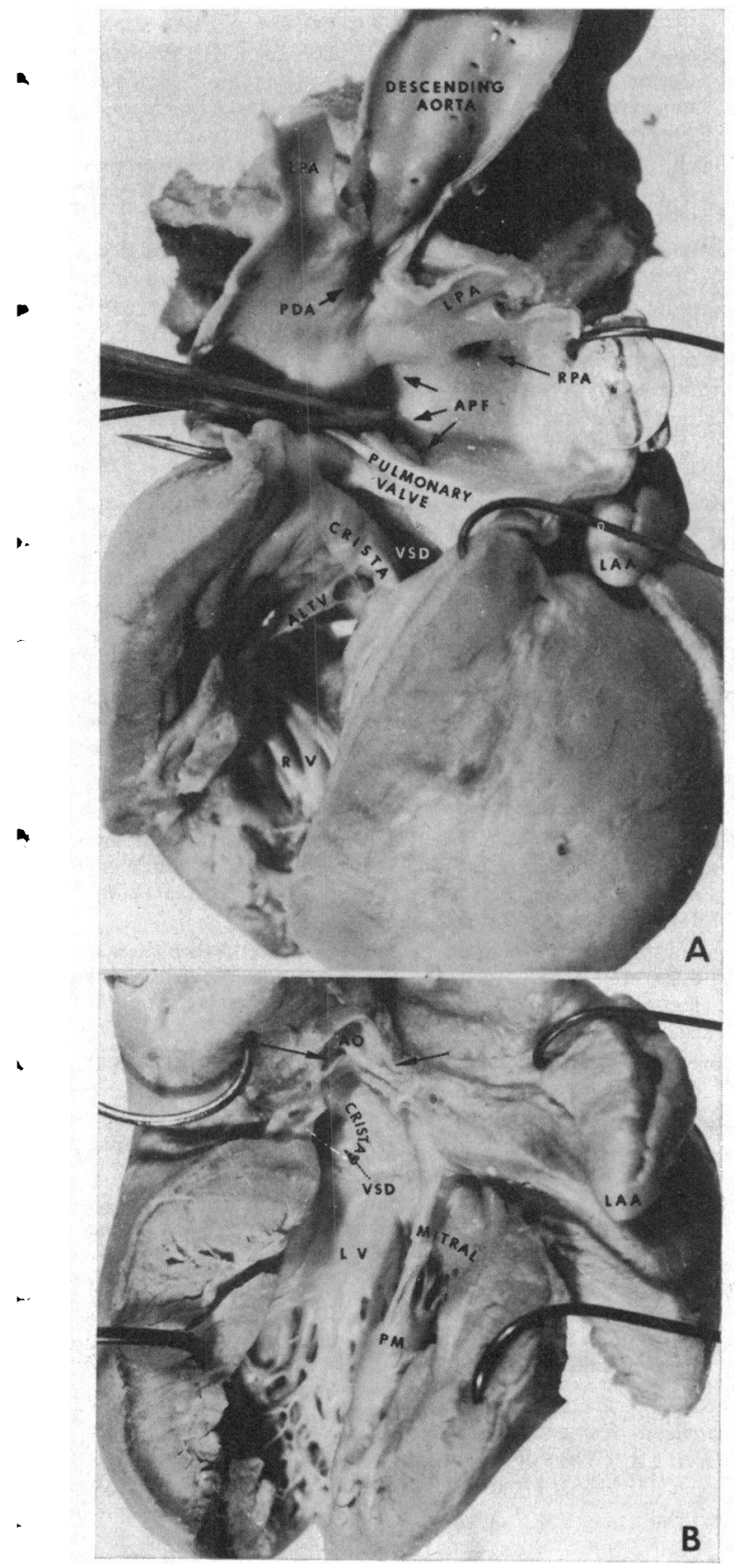

gave rise to the innominate and left common carotid arteries; the arch was interrupted. The pulmonary veins returned normally to the left atrium, which was normal in size. The mitral valve annulus was $8 \mathrm{~mm}$ in diameter. Though its papillary muscles were normally formed, the length of the free margin of the anterior cusp was restricted, a feature of the hypoplastic mitral valve (Rosenquist, 1974). The left ventricle was $27 \mathrm{~mm}$ in length from mitral annulus to apex. Its only exit was the ventricular septal defect, which measured $5 \mathrm{~mm}$ in diameter (Fig. IA).

\section{Discussion}

Although the combination of lesions described here (Fig. 2) has not been reported previously, the haemodynamic disturbance resembles that of truncus arteriosus (type I, subtype 5 of Collett and Edwards [1949] and type A4 of Van Praagh and Van Praagh [1965]), because one outflow valve leads from the heart to a great vessel that supplies blood to systemic, pulmonary, and coronary circulations and there is atresia of part of the aortic arch.

The circuitous route from left ventricle to coronary circulation included successively, the ventricular septal defect, right ventricular outflow tract, pulmonary valve, main pulmonary artery, aortopulmonary fenestration, root of aorta, and finally, in retrograde fashion, aortic sinus and coronary artery.

It is unlikely that the systolic murmur represented flow across the ventricular septal defect, because the defect was very large; probably it was related either

FIG. I A) View of opened right ventricle (RV), pulmonary arteries and descending aorta. The aortopulmonary fenestration ( $A P F$, arrows and probe) is an oval opening between the main pulmonary artery and the root of the aorta. The ventricular septal defect (VSD) is in the supracristal position. The pulmonary valve is bicuspid. Right and left pulmonary arteries (RPA, LPA) and persistent ductus arteriosus $(P D A)$ arise from the main pulmonary artery. $L A A$ : left atrial appendage; $A L T V$ : anterior leaflet, tricuspid valve. B) Opened left ventricle (LV). The posteromedial papillary muscle (PM) supports a mitral valve that is normally formed, though the free margin of the anterior leaflet is restricted. The ventricular septal defect (VSD, interrupted arrow) leads into the right ventricular outflow tract. AO: opened aorta above the atretic aortic valve. The coronary arteries (solid arrows) arise from rudimentary sinuses in the narrow base of the root of the aorta. LAA: left atrial appendage. 


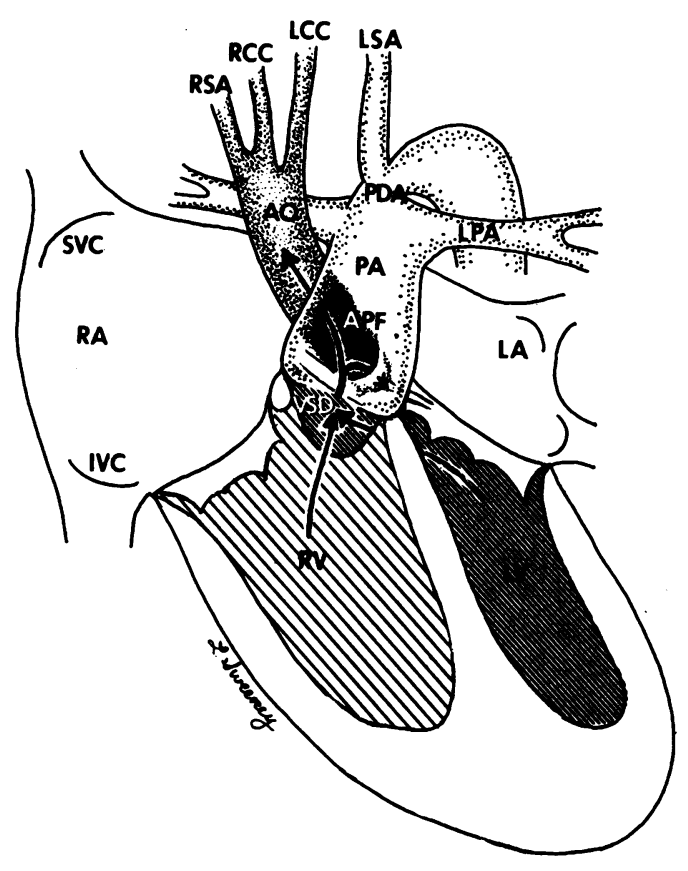

FIG. 2 Drawing to illustrate the pathological anatomy of the reported case. Anterior view, similar to Fig. IA. Abbreviations: IVC: inferior vena cava; LA: left atrium; LCC: left common carotid artery; LSA: left subclavian artery; $P A$ : pulmonary artery; $R A$ : right atrium; RCC: right common carotid artery; RSA: right subclavian artery; SVC: superior vena cava. Other abbreviations as in Fig. IA and $\mathrm{B}$.

to increased flow through the bicuspid pulmonary valve, or to flow of blood at the narrow persistent ductus arteriosus. The latter seems the most likely explanation, since the blood pressure in the left arm and legs was diminished.

Aortography should differentiate this condition from truncus arteriosus. Definitive repair in this instance would not be possible because of the aortic atresia, though the other lesions could all be corrected individually. Palliative treatment seems to be limited to banding the right and left pulmonary arteries separately and creating an adequate vascular pathway to the descending aorta.

The authors thank Dr. Colin Berry for the original necropsy findings, Dr. R. E. Bonham-Carter for permission to publish the case, Lauren Sweeney for Fig. 2, Gary Sterner for the photographs in Fig. I, and Soame D. Christianson for help in preparation of the manuscript.

\section{References}

Bosher, L. H., Jr., and McCue, C. M. (1962). Diagnosis and surgical treatment of aorto-pulmonary fenestration. Circulation, 25, 456.

Collett, R. W., and Edwards, J. E. (1949). Persistent truncus arteriosus: a classification according to anatomic types. Surgical Clinics of North America, 29, 1245.

Dadds, J. H., and Hoyle, C. (1949). Congenital aortic septal defect. British Heart fournal, 11, 390.

Deverall, P. B., Lincoln, J. C. R., Aberdeen, E., BonhamCarter, R. E., and Waterston, D. J. (1969). Aortopulmonary window. fournal of Thoracic and Cardiovascular Surgery, 57, 479.

Gasul, B. M., Fell, E. H., and Casas, R. (I95I). The diagnosis of aortic septal defect by retrograde aortography. Report of a case. Circulation, 4, 251.

Gross, R. E. (1952), Surgical closure of an aortic septal defect. Circulation, 5, 858 .

Hurwitz, R. A., Ruttenberg, H. D., and Fonkalsrud, E. (1967). Aortopulmonary window, ventricular septal defect and mesoversion. Surgical correction in an infant. American fournal of Cardiology, 20, 566.

Kalter, J. E., Pauzner, Y. M., Shem-tov, A., and Deutsch, V. (1970). Aortopulmonary septal defect. fournal of Cardiovascular Surgery, 11, 321.

Meisner, H., Schmidt-Habelmann, P., Sebening, F., and Klinner, W. (r968). Surgical correction of aorto-pulmonary septal defects. A review of the literature and report of eight cases. Diseases of the Chest, 53, 750.

Morrow, A. G., Greenfield, L. J., and Braunwald, E. (1962). Congenital aortopulmonary septal defect. Circulation, 25, 463.

Neufeld, H. N., Lester, R. G., Adams, P., Jr., Anderson, R. C., Lillehei, C. W., and Edwards, J. E. (1962). Aorticopulmonary septal defect. American fournal of Cardiology, 9, 12.

Putnam, T. C., and Gross, R. E. (1966). Surgical management of aortopulmonary fenestration. Surgery, 59, 727.

Reis, R. L., Gay, W. A., Jr., Braunwald, N. S., and Morrow, A. G. (1965). The gradual closure of aorto-pulmonary septal defects. Fournal of Thoracic and Cardiovascular Surgery, 48, 955 .

Rosenquist, G. C. (1974). Congenital mitral valve disease associated with coarctation of the aorta: a spectrum that includes parachute deformity of the mitral valve. Circulation. In the press.

Sprengel, R. A., and Brown, A. F. (1954). Aortic septum defect. American Heart fournal, 48, 796.

Stanley, P., Jeanty, G., Éthier, M., and Davignon, A. (1969). Fenêtre aortopulmonaire. A propos de quatre cas opérés. Union Médicale du Canada, 98, 1473.

Wright, J. S., Freeman, R., and Johnston, J. B. (1968). Aorto-pulmonary fenestration. Fournal of Thoracic and Cardiovascular Surgery, 55, 280.

Van Praagh, R., and Van Praagh, S. (1965). The anatomy of common aorticopulmonary trunk (truncus arteriosus communis) and its embryologic implications. A study of 57 necropsy cases. American fournal of Cardiology, 16, 406.

Requests for reprints to Dr. G. C. Rosenquist, The Helen B. Taussig Children's Cardiac Center, The Johns Hopkins Hospital, Baltimore, Maryland 21205, U.S.A. 